\title{
An Update in Management of Snoring and Sleep Apnoea
}

\section{Yousuf Saleem MS; FRCS(ENT); FRCS(ORL) ENT Consultant}

\section{St. Helens \& Knowsley Teaching Hospitals United Kingdom}

Video

Snoring, alone, is a social/cosmetic problem, and is not associated with significant health problems

Most people who snore do not have OSA However, almost all patients with OSA are heavy snorers; silent OSA can be found in some post- surgical patients

Current sleep diagnostic technology does not support the ENT surgeon.

Sleep medicine is dominated by CPAP

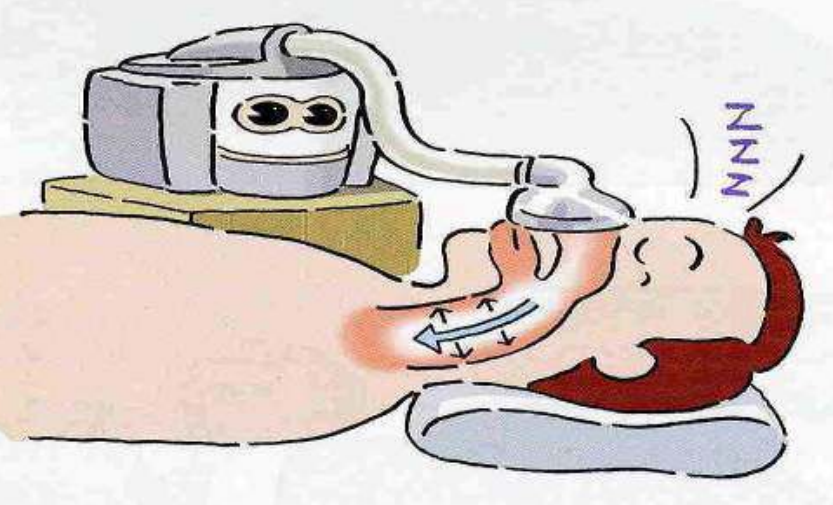

But: Poor compliance is most common in mild apnoea

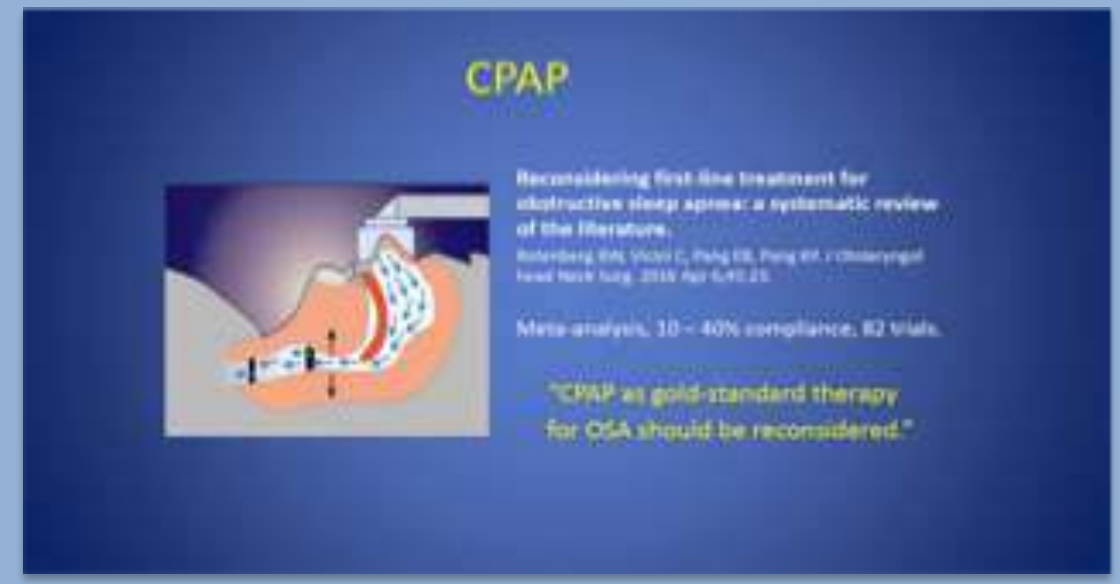

AHI
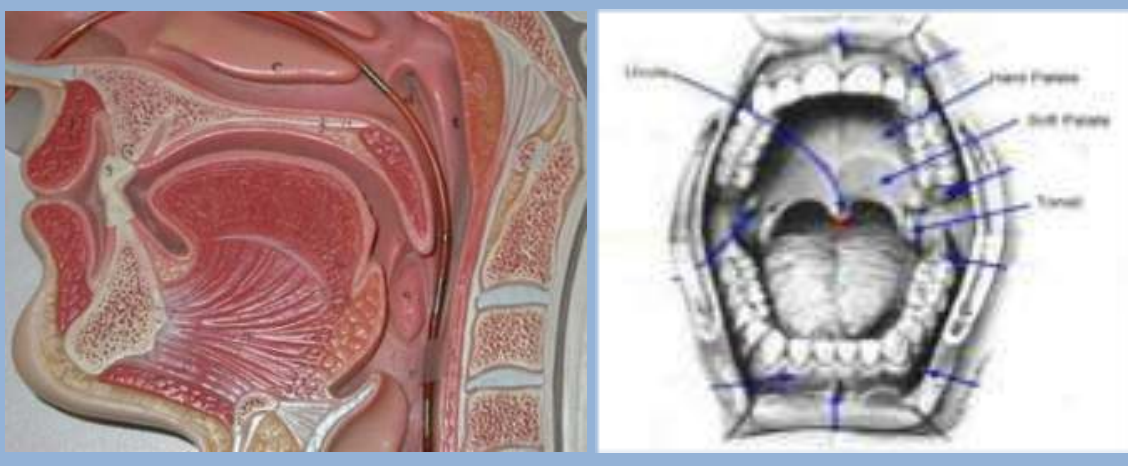

Determination of

Obstruction Site

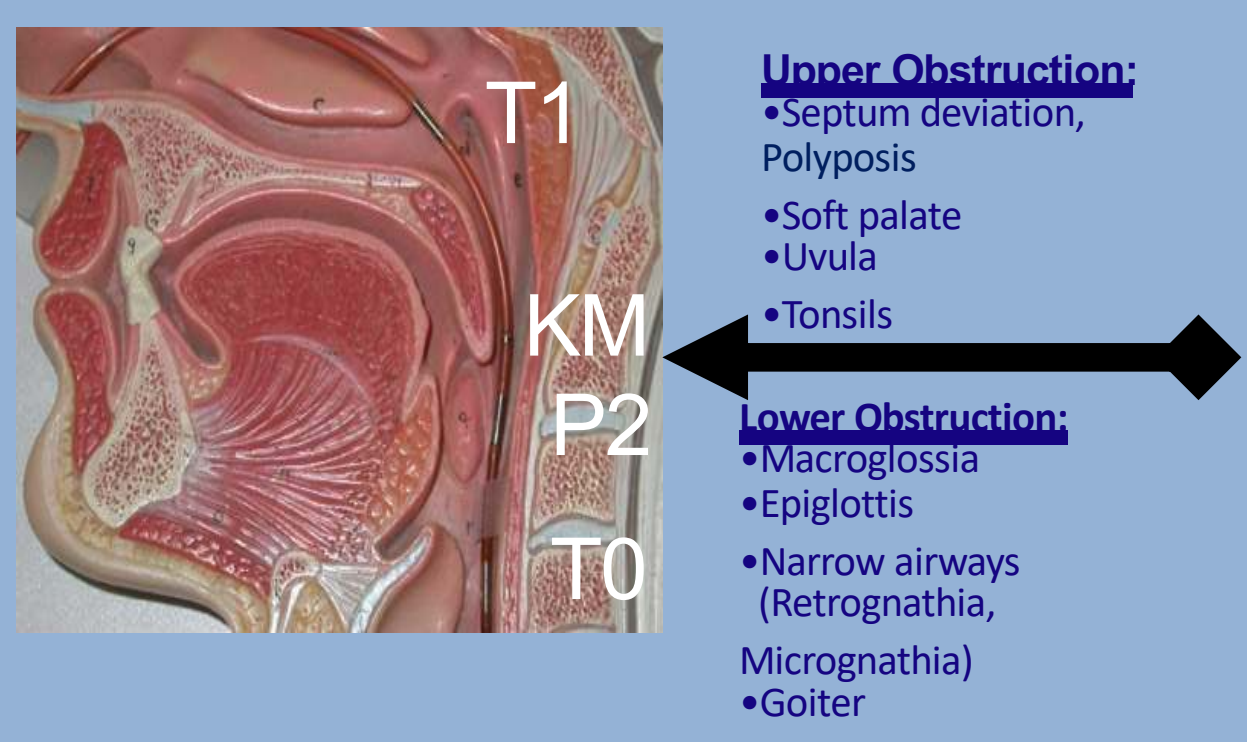

Upper Obstruction

Diagnosis Established

$O S A=A H I+R E R A=R D I$.

$5<$ RDi $<15$; Mild

$15<$ RDI $<30$; Moderate

OSA $\approx$ RERA + AHI $=$ RDI

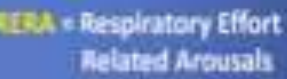

NAs = Apnea/ Hypopnes

Bi: Repiratar postess

$30<\mathrm{ROI} ;$ Serious.

Which TREATMENT to choose?
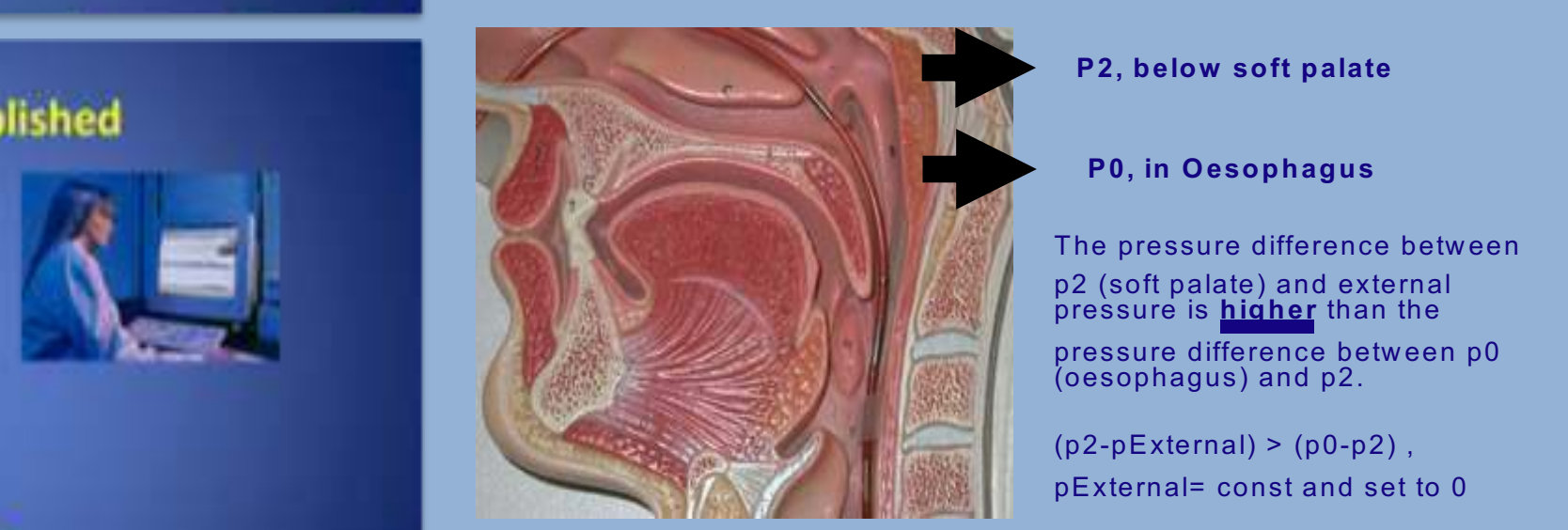

Lower Obstruction

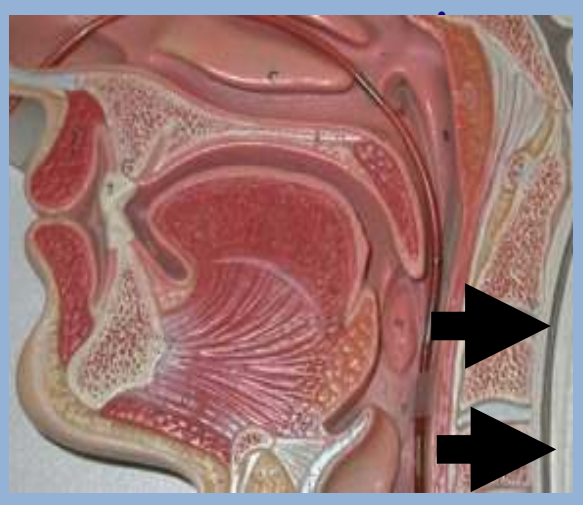

2 (soft palate) and external

pressure is lower than the

(oesophagus) and $\mathrm{p} 2$.

(p2-pExternal) $<(\mathrm{p} 0-\mathrm{p} 2)$,

P2, below soft palate

$\mathrm{P0}$, in Oesophagus

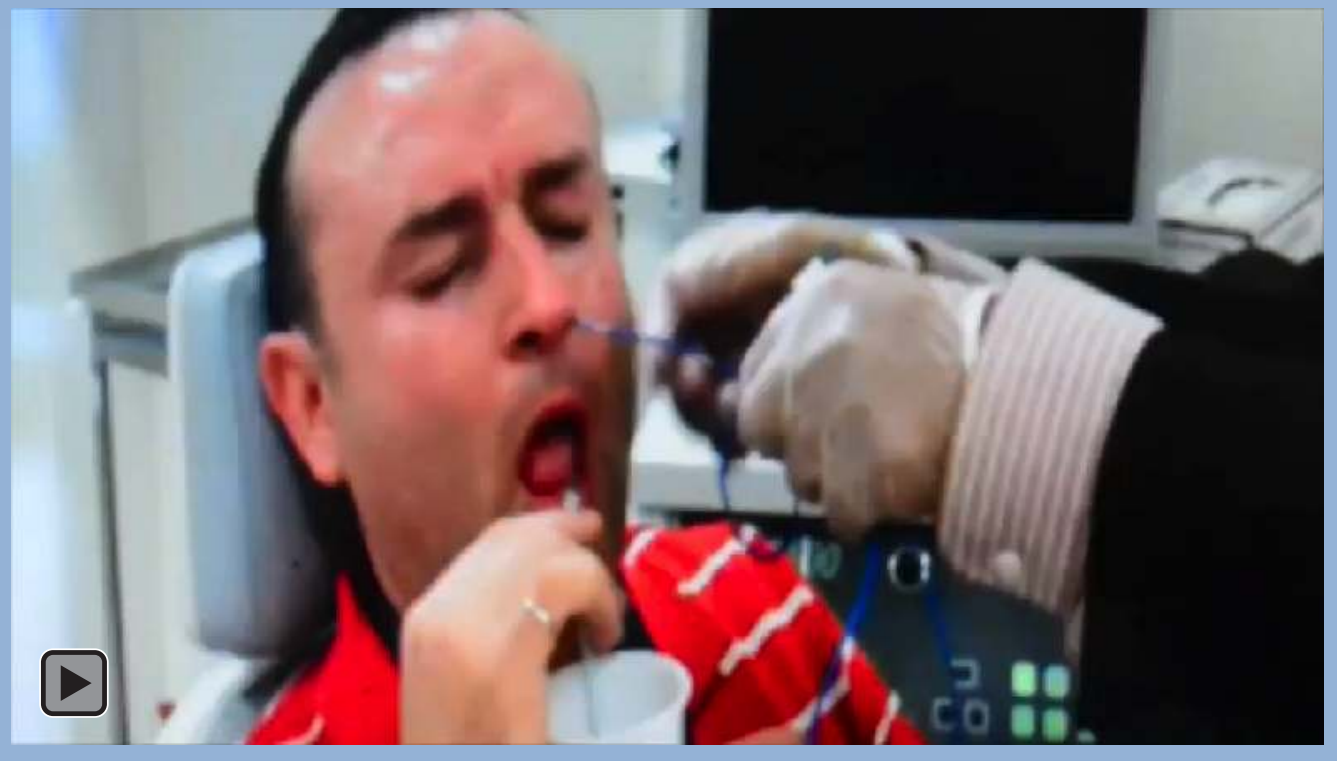

ApneaGraph Recording parameters

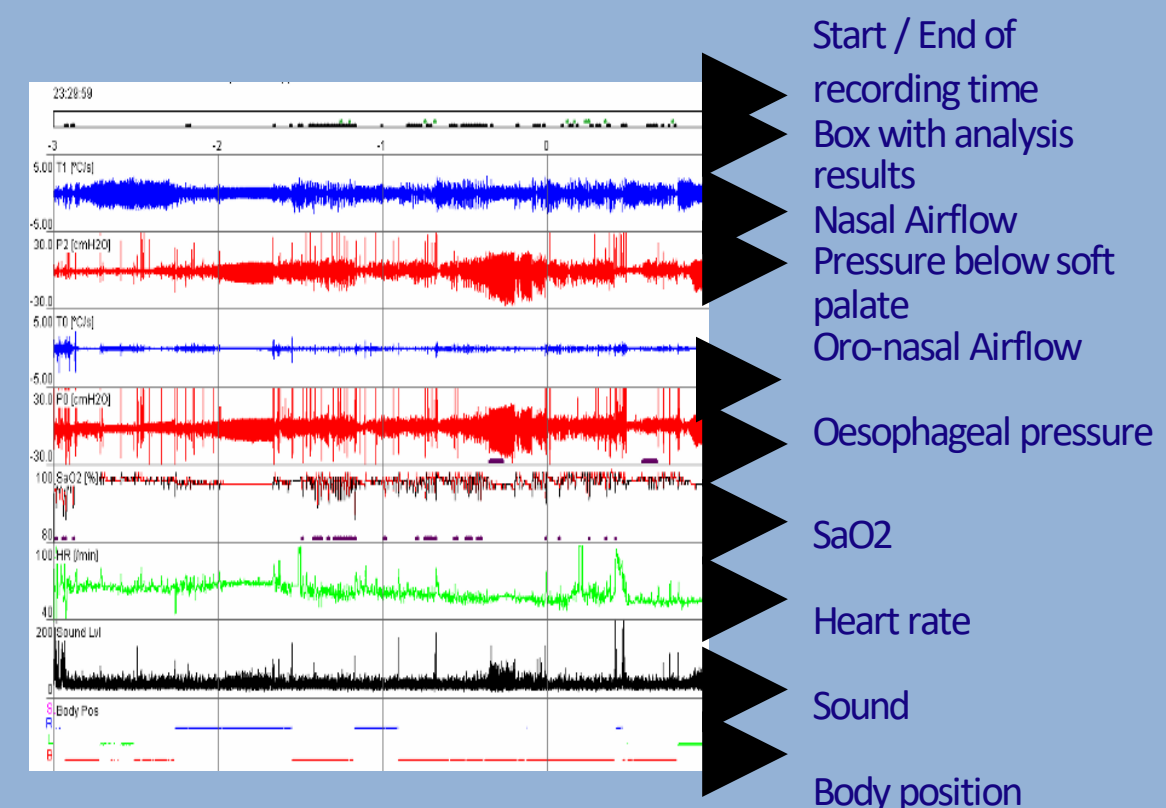

\section{Diagnosing SRBD}

SRBD $=$ RERA + OSA = RDI

RERA = Respiratory Effort Related Arousals= Arousals during increased Lung work.

OSA $=$ Obstructive Sleep Apnea $=$ AHI

(Apnoeas, Hypopneas, Asleep/Awake.)

RDI = Respiratory Distress Index

These parameters give the Complete Diagnosis.

\section{Non Surgical Approaches}

Nasal / Oral Appliances POSA - Treatment. CPAP

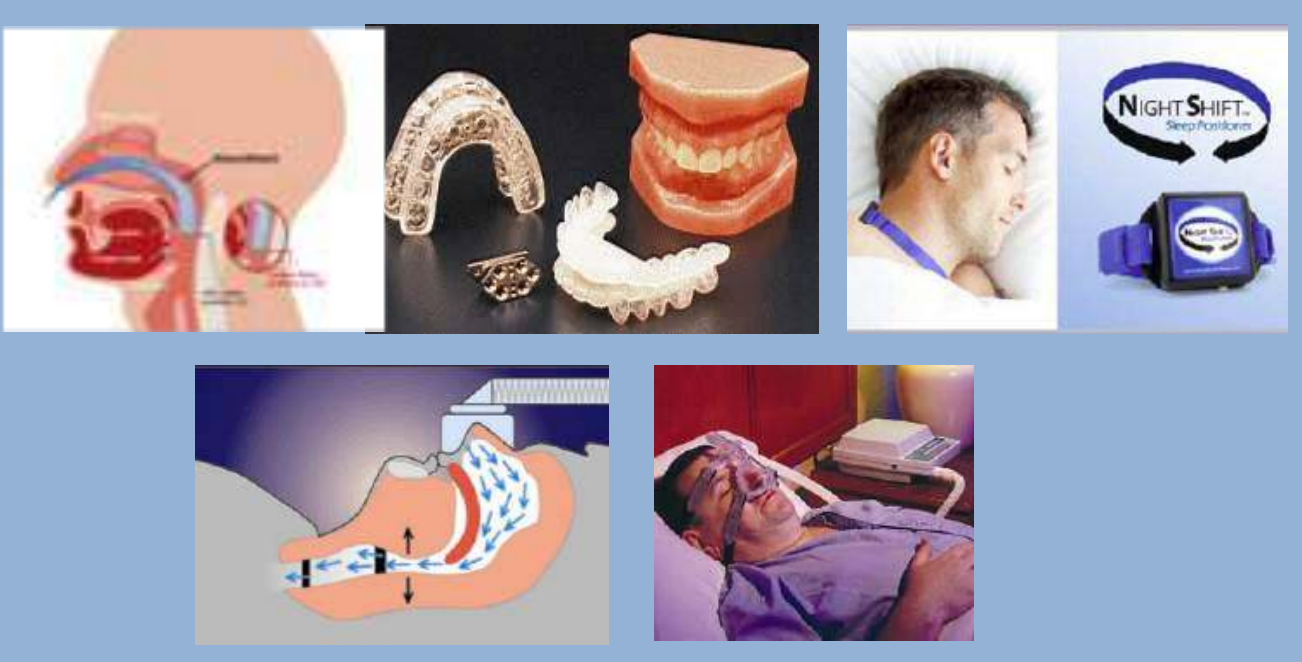

\section{COBLATION TECHNOLOGY}

Low temperature plasma excision

Uses electrical energy to excite the electrodes in a conductive medium like Saline

Creates precisely focused plasma

Energized plasma particles break the organic molecula bonds causing tissue dissection \& ablation

Surface temperature between $40-70 \mathrm{C}$ 